\title{
Dermatology
}

Dermatology 2010;220:49-50

DOI: $\underline{10.1159 / 000258050}$

\section{Lenalidomide-Induced Acute Acneiform Folliculitis of the Head and Neck: Not Only the Anti-EGF Receptor Agents}

\section{Carine Michot, Bernard Guillot, Olivier Dereure}

Department of Dermatology, Hôpital Saint-Eloi, University of Montpellier I, Montpellier, France

\section{Key Words}

Lenalidomide $\cdot$ Acneiform $\mathrm{rash} \cdot$ Folliculitis

Lenalidomide is a thalidomide-related immunomodulating molecule with anti-tumoral and anti-angiogenic properties. It is currently used in multiple myeloma, myelodysplastic syndromes and systemic amyloidosis either in monotherapy or in combination with dexamethasone [1]. Cutaneous side effects have been reported, as with thalidomide, the large majority being low-grade maculopapular rashes. Conversely, the occurrence of acneiform eruptions very much alike anti-epidermal growth factor receptor (EGFR)-related skin complications have been far more rarely reported. Here, we report a new case illustrating this unusual side effect and underscoring that it is not specific to anti-EGFR agents.

A 75-year-old patient had initially been treated with bortezomib (Velcade ${ }^{\circledR}$ ) for multiple myeloma until this molecule proved ineffective and was subsequently replaced by a combination of lenalidomide and dexamethasone with therapeutic cycles of 3 weeks interrupted by a week without treatment. At the end of the third cycle, an acute eruption involving the head and neck region suddenly occurred with numerous indolent or slightly itching papular inflammatory elements, most of them topped by a pustule (fig. 1). Other skin regions and the mucous membrane were spared by the eruption, and clinical examination was otherwise unremarkable. After a slight remission during the intercycle week, the lesions significantly worsened during the following course of treatment and lenalidomide was interrupted owing to its likely role in the cutaneous rash. A skin biopsy was performed on a head pustule, which displayed a suppurative and ruptured folliculitis, the follicle having been invaded by sheets of altered neutrophils (fig. 2). The bacterial swab remained sterile, whereas mycological sampling revealed the presence of numerous Candida albicans. A first-line treatment with topical desonide and doxycycline $100 \mathrm{mg} /$ day was introduced, along with fluconazole $50 \mathrm{mg} /$ day during the first 2 weeks. Cutaneous inflammatory elements progressively improved, and the patient was almost free of lesions after 3 months of treatment with cyclins.

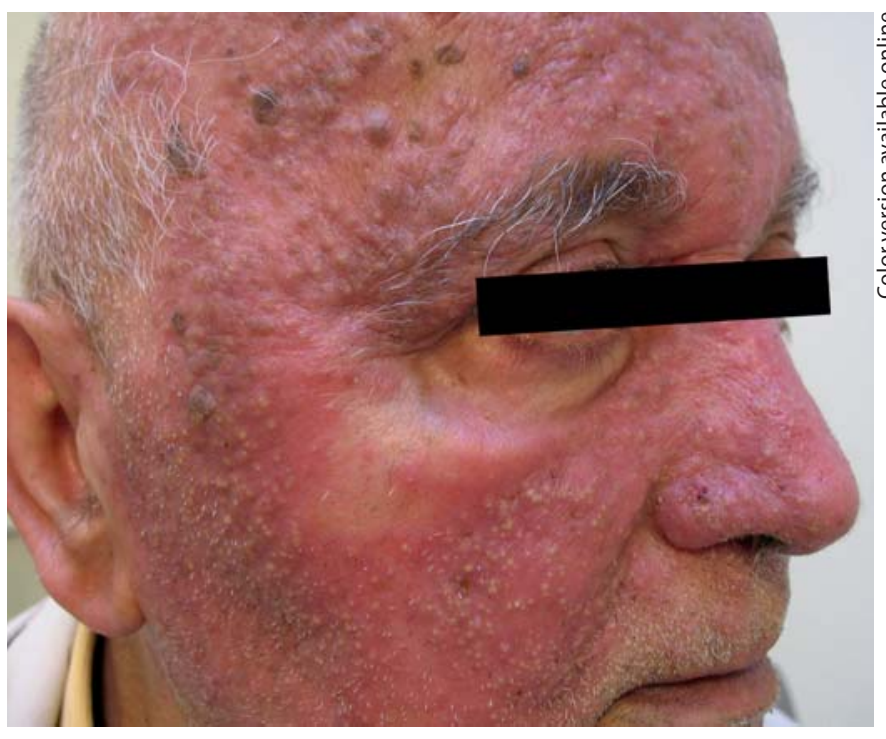

Fig. 1. Acute papulopustular eruption of the head and neck.

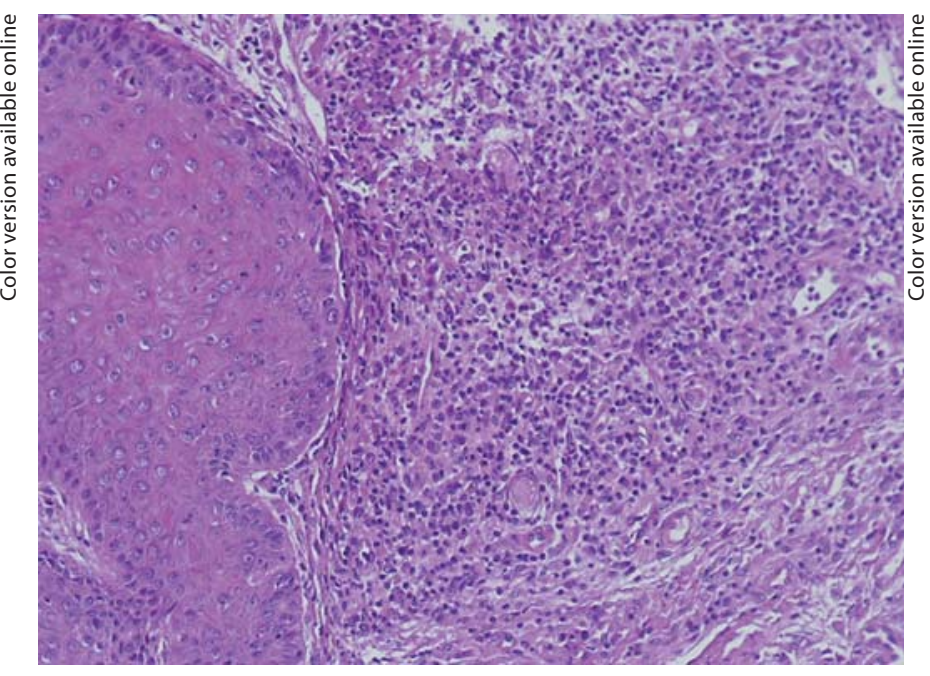

Fig. 2. Skin biopsy of a head pustule: ruptured folliculitis with sheets of altered neutrophils.

\section{KARGER}

(ㄷ) 2009 S. Karger AG, Basel

Fax +4161306 1234 E-Mail karger@karger.ch www.karger.com 
A specific assessment of lenalidomide-related cutaneous adverse effects has been performed only once, and this single report showed that skin complications occur in approximately one third and in $43 \%$ of patients treated for myeloma and systemic amyloidosis, respectively [2]; a combination with dexamethasone, especially in myeloma, does not significantly modify this incidence. Regarding thalidomide, the main clinical pattern is a maculopapular inflammatory rash with no criteria of severity in most cases, whereas urticarial or eczematous lesions are more unusual and toxic epithelial necrosis has been reported in individual cases only $[2,3]$. In most patients, skin lesions appear within the first month of treatment, although their occurrence may be delayed up to 4 months after the introduction of the molecule. The occurrence of pustular aseptic elements has only been reported in 2/75 patients receiving lenalidomide, and it is noteworthy that it has also been described with thalidomide, but with no clear estimation of its incidence [3]. Our observation confirms this possibility and underscores that the clinical pattern of this adverse effect cannot be easily distinguished from the well-known anti-EGFRagent-induced head and neck folliculitis, a data overlooked by previous clinical reports. Accordingly, it can be concluded that drug-induced head and neck folliculitis is not restricted to molecules that mainly interfere with EGFR-related pathways, but can also occur with TNF $\alpha$ modifiers since this cytokine and its network represent one of the main targets of lenalidomide. Nevertheless, it is of interest to point out that a direct link with EGFR-dependent events may still be a relevant hypothesis to explain this unusual side effect, since it has recently been demonstrated that thalidomide may interfere with some EGFR-dependent intracellular signaling pathways [4]. Furthermore, lenalidomide is also characterized by its ability to interfere with tyrosine kinases, which underlies its VEGF-inhibiting properties, and 'EGFR inhibitor-like' cutaneous side effects have already been reported with other drugs interfering with kinases, like sirolimus and mesylate imatinib $[5,6]$, thus suggesting the development of tyrosine-kinase-inhibitor-related pustular eruptions as an overall concept. Although an additional role of $C$. albicans cannot be ruled out in our observation, its direct responsibility in the onset of the lesions remains doubtful since the clinical pattern did not fit the usual picture of Candida folliculitis. The patient was not considered to be significantly immunosuppressed, and treatment with fluconazole did not result in a dramatic improvement in the eruption, which instead progressively cleared over several weeks.

Whatever its underlying mechanisms may be, this unusual side effect of lenalidomide must be kept in mind since this molecule will probably become increasingly used in the future. Treatment of this complication has not been defined, but a combination of cyclins and topical steroids was successful in our patient, by analogy with anti-EGFR-agent-induced folliculitis. However, the specificity of this response cannot be ensured owing to the simultaneous interruption of the inducing molecule.

\section{References}

1 Rajkumar SV, Hayman SR, Lacy MQ, et al: Combination therapy with lenalidomide plus dexamethasone (REV/DEX) for newly diagnosed myeloma. Blood 2005;106:4050-4053.

2 Sviggum HP, Davis MDP, Rajkurmar SV, Dispenzieri A: Dermatologic adverse effects of lenalidomide therapy for amyloidosis and multiple myeloma. Arch Dermatol 2006;142:1298-1302.

-3 Hall VC, El-Azhary RA, Bouwhuis S, Rajkumar SV: Dermatologic side effects of thalidomide in patients with multiple myeloma. J Am Acad Dermatol 2003;48:548-552.

4 Noman AS, Koide N, Khuda II, Dagvadorj J, Tumurkhuu G, Naiki Y, Komatsu T, Yoshida T, Yokochi T: Thalidomide inhibits epidermal growth factor-induced cell growth in mouse and human monocytic leukemia cells via Ras inactivation. Biochem Biophys Res Commun 2008;374:683-687.

5 Gambillara E, Laffitte E, Widmer N, Decosterd LA, Duchosal MA, Kovacsovics T, Panizzon RG: Severe pustular eruption associated with imatinib and voriconazole in a patient with chronic myeloid leukemia. Dermatology 2005;211:363-365.

-6 Kunzle N, Venetz JP, Pascual M, Panizzon RG, Laffitte E: Sirolimusinduced acneiform eruption. Dermatology 2005;211:366-369.

Olivier Dereure

Department of Dermatology, Hôpital Saint-Eloi

80 avenue Augustin Fliche

FR-34295 Montpellier Cedex 5 (France)

Tel. +33467336906, Fax +33467336958

E-Mail o-dereure@chu-montpellier.fr 